\title{
Flight Nurse Turnover: Where They Go, Why, and What They Do
}

\author{
Ann D. Frederick, RN, and Richard E. Burney, MD
}

TURNOVER OF PERSONNEL IS A MAJOR concern in the nursing profession, particularly in the fields related to critical care. ${ }^{1}$ This is no less true in flight nursing, where the investment in time and training is enormous and experience is highly valued. Despite the importance of this issue, little information exists regarding job turnover among flight nurses. ${ }^{2,3,4}$

This study was undertaken to learn more about turnover among flight nurses, specifically how often experienced flight nurses leave the field, why they choose to leave, and where flight nurses' career paths lead after they leave flight nursing.

\section{Methods}

To obtain the names of experienced flight nurses who had left air medical programs after two or more years of employment, questionnaires were sent to chief flight nurses from 53 hospital-based air medical programs. These names were obtained from the Association of Air Medical Services (AAMS) Membership Directory in 1986. The programs had been in operation for a minimum of two years prior to July 1984 .

In addition, a notice was placed in one publication of the aeroMedical Journal stating that former flight nurses were needed to respond to a questionnaire. A "former flight nurse" was defined as a nurse active in flight nursing for a minimum of two years, but no longer flying, even if he or she was still involved in some other capacity with a flight program. A total of 80 names were compiled from these sources.

The questionnaire also solicited data about flight program operations and policies, including years of program operation, crew configuration, shift hours, flight nurse hourly pay, compensation or reimbursement for continuing education, and the presence of a clinical ladder.

Other data solicited included general flight nurse requirements and qualifications, number of flight nurses presently employed, and the number that had resigned since the inception of the program.

A second questionnaire was sent to the 80 former flight nurses (FFNs). This questionnaire requested their present position, number of years as both staff and flight nurse, total years in nursing, position before flight nursing, and degrees held.

The questionnaire also asked if the degree or degrees were obtained while employed as a flight nurse, reasons for leaving, things most missed about flight nursing since leaving, and plans to return to a position as a flight nurse in the future. Eleven reasons for leaving were listed; FFNs were to choose their top three. FFNs were also asked to rank, in order of importance, what they missed most about flight nursing from a list of nine options. A space was provided for additional comments.

\section{Results}

This survey was carried out in 198687. Responses were received from all 53 chief flight nurses. The programs that these nurses represented had been in operation an average of 5.8 years (range two to 14). An average of 10 flight nurses were employed per program, with a range of four to 39 . The crew configuration was nurse/paramedic in 15 programs (28\%), nurse/physician in $12(23 \%)$, and nurse/nurse in six (11\%). There were four programs with one nurse only, one each with RN/RRT and RN/PA-C, and 14 (38\%) with the crew configurations depending on the type of flight.

In comparing the crew configurations for the programs surveyed to the recently published data in The Journal of Air Medical Transport, the percentages are similar. ${ }^{3}$ The majority were two-attendant crews, with $\mathrm{RN} /$ paramedic as the highest percentage, $\mathrm{RN} /$ physician, and two-nurse crew complement to follow, respectively.

The general requirements or qualifications required of flight nurses included between two and five years of critical care experience, and, in some cases, specific ER or ICU experience. ACLS was required by 48 programs (91\%) and preferred by four (8\%). A-EMT certification was required or 
preferred by 34 programs (64\%) and EMT-P by $20(38 \%)$ of the programs. Either a CCRN and/or CEN were required or preferred by 43 programs (81\%).

Either partial or full reimbursement to obtain a bachelor's degree was provided by 31 programs (58\%) and by 25 (47\%) for a master's level degree. Twelve programs (23\%) provided reimbursement for other degrees.

Additional compensation for higher level degrees was less common: only six programs (11\%) paid more for a BSN, three (6\%) for an MSN, and two (4\%) for other degrees. Nineteen programs (36\%) had some kind of clinical ladder in place for evaluation and advancement.

Thirty-one programs (58\%) worked 12-hour shifts, and 10 (19\%) had 24hour shifts. Eleven programs (21\%) varied their shifts, and two programs each $(4 \%)$ had 8-hour and 10-hour shifts.

Hourly pay varied greatly among programs as well as within the programs. The lowest hourly rate was $\$ 8.29$, the highest $\$ 19.50$; the average was $\$ 12.73$.

Forty-eight chief flight nurses (91\%) provided the number of flight nurses that had resigned from their programs since they began operation. The average number of total resignations during all years of program operation was 8.5 , with a range of one to 50 . Taking an average of 5.76 years of program operation, the mean number of flight nurses/program/year that had resigned was 1.5 , equivalent to a $17 \%$ annual turnover rate. In averaging the

\section{The three reasons most} often chosen for leaving flight nursing were family reasons, environmental safety, and hours-night shift or overtime.

annual turnover rate per program, the range was from 0 to 5.6 , with an average of 1.4 flight nurses/program/year. This average of 8.5 flight nurse resignations is equivalent to a $17 \%$ annual turnover rate.

From FFNs, 48 questionnaires $(60 \%)$ were returned. Four of these were invalid (three flight nurses had not been in flight nursing at least two years, and one form was incomplete), leaving a total of 44 (55\%) for further analysis. These questionnaires were filled in anonymously so that direct correlation between individual nurses and programs could not be obtained.

The respondents had been nurses for an average of 11.74 years and had spent an average of 3.37 years as flight nurses. Before being flight nurses, about one-half (21 FFNs, 48\%) had been ED staff nurses; the other half were evenly divided between ICU staff nursing (9 FFNs, 20\%) and nursing supervisory positions (three each in $\mathrm{ED}$, ICU/hospital and pediatrics).

There were a total of 21 advanced degrees among the 44 respondents (48\%), $12 \mathrm{BSN}$, two MSN, and seven other degrees. Five $(11 \%)$ were obtained while working as flight nurses. The degrees may have been required by the flight program or may have been compensated in some way if a degree was held, according to the results of the chief flight nurse survey.

The three reasons most often chosen for leaving flight nursing were family reasons, environmental safety, and hours-night shift or overtime (Table 1). Twenty-four FFNs (54\%) chose family reasons as one of their top three; 15 (34\%) chose it as the No. 1
Family reasons

Environmental safety

Hours-night shift or overtime

Career advancement

Conflicts with administration

To further education

Left institution with flight program

Physical reasons

Not challenging enough

Conflicts with other departments

Increase pay

*Weighted Values: $\# 1=3$ points

\#2 = 2 points

\#3 = 1 point

\section{Table 1}

Reasons for Leaving Flight Nursing $n=44$

$\begin{array}{crc}\begin{array}{c}\text { Weighted } \\ \text { Total }\end{array} & & \\ 59 & 15 & (34 \%) \\ 38 & 6 & (14 \%) \\ 31 & 1 & (2 \%) \\ 26 & 6 & (14 \%) \\ 25 & 3 & (7 \%) \\ 22 & 5 & (11 \%) \\ 16 & 3 & (7 \%) \\ 11 & 1 & (2 \%) \\ 10 & 2 & (5 \%) \\ 9 & 1 & (2 \%) \\ 1 & 0 & (0 \%)\end{array}$

$\begin{array}{rc} & \# 3 \\ 4 & (9 \%) \\ 4 & (9 \%) \\ 11 & (25 \%) \\ 2 & (5 \%) \\ 6 & (14 \%) \\ 1 & (2 \%) \\ 1 & (2 \%) \\ 11 & (25 \%) \\ 2 & (5 \%) \\ 0 & (0 \%) \\ 1 & (2 \%)\end{array}$

\begin{aligned} & \multicolumn{2}{c}{ Total \# of } \\ & Times Chosen \\ & 24$(54 \%) \\ & 18(41 \%) \\ & 20.5(46 \%) \\ & 11(25 \%) \\ & 14(32 \%) \\ & 9(20 \%) \\ & 7(16 \%) \\ & 6.5(15 \%) \\ & 5(11 \%) \\ & 4(9 \%) \\ & 1(2 \%)\end{aligned}$


reason. Eighteen FFNs (41\%) chose environmental safety as one of the top three reasons for leaving; six (14\%) chose it as the top reason. Although 19 (43\%) chose hours among the top three reasons, only one ranked it No. 1. One FFN chose physical reasons and hours as a combined No. 2 reason for leaving, stating, "tied in with hours worked ... shifts rotated day to day, 12-hour shifts."

The next most common reasons for leaving were career advancement (11 FFNs, or $25 \%$, six No. 1 rankings), conflicts with administration (14 FFNs, 32\%, three No. 1 rankings), and to fur ther education ( $9 \mathrm{FFNs}, 20 \%$, five No. 1 rankings). Seven (16\%) left the institution with the flight program (three No. 1 rankings); physical reasons were cited by six FFNs (14\%, one No. 1 ranking); and one FFN cited increase in pay.

At the time of the survey, five of the FFNs that chose "conflict with administration" as one of the three reasons for leaving were emergency department staff nurses, three were in supervisory/educational positions, two were unemployed, two were either ED staff nurses or in other staff positions, and one was a doctor of chiropractic medicine. Three of the FFNs that chose "not challenging enough" as one of the three reasons for leaving were in other staff positions, and one was in a supervisory/educational position.
Of note is the frequency with which family and safety were cited as the chief reasons for leaving flight nursing. Thirty-one FFNs (74\%) surveyed $(\mathrm{N}=42)$ answered family or safety as being one of the top three reasons for leaving. Ten FFNs (32\%) out of those answered family reasons and safety as reasons for leaving.

Of interest also is the frequency with which two other reasons, safety and conflicts with administration, were linked. Twenty-three FFNs (55\%) surveyed $(\mathrm{N}=42)$ answered safety or conflict with the administration as a top three reason for leaving. Seven (30\%) out of those 23 answered safety and conflicts with administration together as reasons for leaving.

In examining the family reasons and hours, we found that $30.5 \mathrm{FFNs}$ $(73 \%)$ surveyed $(\mathrm{N}=42)$ answered fam- ily reasons or hours as a top three reason for leaving. Fourteen ( $46 \%$ ) out of 30.5 answered family reasons and hours as two of the top three reasons for leaving flight nursing.

After leaving flight nursing, 17 FFNs (39\%) went on to supervisory positions, 11 (25\%) joined the nursing staff in an emergency department, and another 11 (25\%) were in widely varied nursing positions. One was a doctor of chiropractic medicine. The remaining 5 FFNs (11\%) were unemployed at the time of the survey (Table 2).

Table 3 illustrates the aspects of flight nursing most commonly missed by FFNs. The nursing challenge was missed most often, independence second, and working with fellow flight crew members third.

Thirty-one FFNs (74\%) who had left flight nursing indicated that they did

\begin{tabular}{|lcc|}
\multicolumn{1}{c|}{$\begin{array}{c}\text { Table 2 } \\
\text { Where Former Flight Nurses Go } \\
\mathrm{n}=44\end{array}$} & \\
& $\mathbf{n}$ & $\%$ \\
& & \\
Supervisory/Educational Positions & 17 & $(39 \%)$ \\
Emergency Department Staff Nurse & 11 & $(25 \%)$ \\
Other Staff Positions & 9 & $(21 \%)$ \\
Other Positions & & \\
Doctor of Chiropractic Medicine & 1 & $(2 \%)$ \\
Nurse Practitioner OB/G & 1 & $(2 \%)$ \\
Unemployed & 5 & $(11 \%)$ \\
& & \\
\hline
\end{tabular}

Table 3

What Do Former Flight Nurses Miss Most?

\begin{tabular}{|c|c|c|c|c|c|c|c|c|c|c|c|c|c|}
\hline & & & $\begin{array}{c}\text { Weighted } \\
\text { Total }^{*}\end{array}$ & \#1 & \#2 & \#3 & \#4 & $\begin{array}{c}\text { Rank } \\
\# 5\end{array}$ & d & \#7 & \#8 & \#9 & $\begin{array}{c}\text { Total \# } \\
\text { Chosen }\end{array}$ \\
\hline Nursing che & nge & & 278 & 9 & 9 & 10 & 3 & 5 & 3 & 0 & 0 & 0 & 39 \\
\hline Independen & & & 243 & 11 & 7 & 5 & 2 & 4 & 4 & 0 & 1 & 3 & 37 \\
\hline Working wit & ellow flight crew & & 206 & 4 & 5 & 6 & 7 & 2 & 6 & 1 & 4 & 1 & 36 \\
\hline Feeling of $h$ & ing an "effect" o & someone's life & 197 & 4 & 6 & 5 & 4 & 3 & 3 & 6 & 3 & 3 & 37 \\
\hline Beauty and & citement of flyir & & 194 & 8 & 3 & 4 & 3 & 3 & 4 & 3 & 4 & 4 & 36 \\
\hline Working wit & MS/ER person & & 180 & 0 & 6 & 6 & 6 & 6 & 1 & 3 & 4 & 3 & 35 \\
\hline Patient con & & & 174 & 6 & 3 & 1 & 3 & 5 & 5 & 5 & 4 & 3 & 35 \\
\hline Continuing & ongoing educ & on for self & 148 & 1 & 2 & 5 & 4 & 3 & 4 & 5 & 6 & 6 & 36 \\
\hline Contact witl & atient families & & 100 & 0 & 2 & 0 & 3 & 2 & 2 & 9 & 6 & 9 & 33 \\
\hline *Weighted: & $\begin{array}{l}\# 1=9 \text { points } \\
\# 2=8 \text { points } \\
\# 3=7 \text { points } \\
\# 4=6 \text { points } \\
\# 5=5 \text { points }\end{array}$ & $\begin{array}{l}\# 6=4 \text { points } \\
\# 7=3 \text { points } \\
\# 8=2 \text { points } \\
\# 9=1 \text { point }\end{array}$ & & & & & & & & & & & \\
\hline
\end{tabular}


not plan to return to positions as flight nurses in the future. Nine (21\%) said they would return, and two (5\%) were undecided. Of the nine that said "Yes" five $(55 \%)$ indicated "family reasons" as the No. 1 reason for leaving.

The other primary reasons for the remaining four were safety, conflicts with administration, leaving the institution with the flight program, and conflicts with other departments. Four of the nine indicated that "independence" was the aspect missed most; two missed the nursing challenge most and two the beauty and excitement of flying. One indicated working with fellow flight crew as the aspect missed most.

In the open-ended portion of the survey, some FFNs elaborated on their reasons for leaving, with safety an obviously emotional issue. "I became more fearful, flying in bad weather," "Flight programs need desperately to include the aviation professionals in their decisions regarding the safety of their operations," and "Flight nurses need to be more insistent on promoting air medical safety ... the high rate of accidents/deaths in EMS is disgraceful" were among the comments. Others praised their years as flight nurses, saying such things as "most exciting," "it is a great challenge and very rewarding!" and an "absolute climax to my nursing career."

\section{Discussion}

We found in this survey a low rate of turnover among flight nurses. In reviewing the literature, documentation of nursing turnover rate is rare, although Prescott and Bowen report a "crude turnover rate" of $30 \%$, and report a variance from 42 to $70 \%$ in an earlier report. ${ }^{1}$ By selecting only wellestablished programs to survey and sending inquiries only to flight nurses with two years or more on the job, we may have underestimated to some extent the actual turnover rate. Even so, turnover among flight nurses would appear to be lower than in other high intensity areas of the hospital environment. ${ }^{1,3}$

Safety is obviously an important issue in the air medical industry today, as appeared in many of the comments that were added by the former flight nurses. Since 1987 the increased emphasis on safety within the air medical community has led to a substantial improvement in the EMS accident rate. It would be of interest to compare these statistics from more recent $F N N$ s with these changes over the years. It would also be interesting to investigate how many of these former flight nurses actually did return to a position as a flight nurse and their reasons for returning.

The frequent citing of both family reasons and safety leads one to believe that the decision to leave flight nursing may have been a family decision for various reasons. Written comments cited "pregnancy" or "newly married" in conjunction with the family reasons, with another person influencing the decision.

\section{Conclusions}

We conclude from this work that flight nurses enjoy many rewarding aspects of the job, including the challenge, the independence, the close teamwork and the actual beauty of flying.

Most of the nurses who left flight nursing moved on to other equivalent or higher positions in nursing; very few left the profession. Flight nurses have a strong career orientation. Flight nursing experience is highly valued and leads to advancement in the nursing profession.

Ann D. Frederick, $R N$, is Chief Flight Nurse for Parkview Samaritan at Parkview Memorial Hospital (Fort Wayne, IN). Richard E. Burney, MD, is Associate Professor of Surgery and Medical Director for the Survival Flight program at the University of Michigan Medical Center (Ann Arbor, MI).

\section{References}

1. Prescott PA, Bowen SA: Controlling Nursing Turnover. Nursing Management 1987; 18(6):62-66.

2. England CG: Aeromedical Staff Turnover. aeroMedical Journal 1986; 7:14-15.

3. Collett HM: 1990 Program Survey.J of Air Med Transport 1990; 9(5):19.

4. Wasnetsky G: Stress vs Distress. Journal of Aeromedical Healthcare 1985; 3/4:17-19.

5. Whitley TW, Benson NH, Allison EJ, et al: Occupational Stress and Job Satisfaction Among Flight Nurses. Hospital Aviation 1989; 7:6-11.

6. Whitley TW, Landis SS, Revicki DA, et al: Stress, Depression and Job Satisfaction, aeroMedical Journal 1988; 11/12:10-14. 